\title{
Aminaphtone therapy in patients with type 1 diabetes and albuminuria: a case report
}

\author{
Concetta Romano ${ }^{1}$, Consuelo Tamburella', Martino Costa ${ }^{1}$, Marco Messina ${ }^{1}$, Anna Lisa Fassari ${ }^{2}$ and Marco Bertini ${ }^{3^{*}}$
}

\begin{abstract}
Introduction: Microalbuminuria in type 1 diabetes is the earliest manifestation of diabetic microangiopathy (nephropathy). To date, the pharmacological approach to microangiopathy has not been shown to be useful. By using aminaphtone to control nephrologic complications of insulin-dependent diabetes mellitus we first obtained a significant improvement in microalbuminuria confirming this new pharmacological approach for insulin-dependent diabetes mellitus organospecific complications control.

Case presentation: After being treated with standard therapy for insulin-dependent diabetes mellitus (insulin) for more than 20 years, a 49-year-old white man affected by insulin-dependent diabetes mellitus adopted the standard therapy aminaphtone for a period of 2 months.

This therapy allowed a significant reduction of proteinuria from baseline evaluation that immediately increased after he stopped aminaphtone therapy.

Conclusions: Aminaphtone therapy, used globally in the treatment and prevention of endothelial dysfunctions, could be an interesting option for patients with insulin-dependent diabetes mellitus with the express purpose of preventing diabetic nephropathy.
\end{abstract}

Keywords: Insulin-dependent diabetes mellitus, Microangiopathy

\section{Introduction}

Microangiopathic complications of diabetes include retinopathy, nephropathy and neuropathy. These complications are specific to diabetes and arise as a result of hyperglycaemia that lasts a long time. Undoubtedly, other metabolic factors, and environmental and genetic factors are involved in the pathogenesis. Diabetic nephropathy affects 20 to $40 \%$ of patients with insulin-dependent diabetes mellitus (IDDM), particularly those with onset before puberty [1] and, probably, those with a hereditary predisposition to hypertension [2]. Patients with diabetes with incipient nephropathy (persistent microalbuminuria) have a 5 to 10 times greater risk of developing proliferative retinopathy than those without albuminuria; furthermore, diabetic nephropathy is almost invariably accompanied by retinopathy. The functional alterations that occur early in the natural history of diabetic nephropathy include microalbuminuria and glomerular hyperfiltration.

\footnotetext{
* Correspondence: bertini@baldaccilab.com

${ }^{3}$ Medical Department, Laboratori Baldacci SpA, Via San Michele degli Scalzi 73, 56124 Pisa, Italy

Full list of author information is available at the end of the article
}

Microalbuminuria is defined as a subclinical increase in the rate of urinary albumin excretion in the range of 30 to $300 \mathrm{mg} /$ day. Microalbuminuria is due to the increased permeability of the glomerular capillaries, probably secondary to increased glomerular capillary pressure [3] and to the loss of negative charge at the level of the glomerular basement membrane.

Patients with IDDM with microalbuminuria have a 20 times greater risk of developing a clinical nephropathy compared to those with a normal albumin excretion [4]. Microalbuminuria is considered a risk factor for diabetic nephropathy and progressive renal failure in diabetes [5-8]. Longitudinal and cross-sectional studies conducted on type 2 diabetes have allowed the identification of risk factors associated with the development of microalbuminuria and the progression of microalbuminuria to diabetic nephropathy. These include: low body mass index, early onset of diabetes, hyperglycaemia, hypertension, dyslipidaemia, cigarette smoking, and a family history of hypertension [9-14]. Although microalbuminuria is considered by many authors to be the early stage of an irreversible process, recent research has not confirmed this view, 
showing that microalbuminuria often returns to its normal value $[15,16]$. The histopathological features characteristic of diabetic kidney disease occur in the glomerulus. The main changes are: increase in the thickening of the glomerular basement membrane, increase of volume of the mesangium, the presence of hyaline deposits and global glomerular sclerosis [17]. The glomerular filtration rate (GFR) is closely related to the surface of the basal membrane of the glomerular capillaries (filtration surface) which is in turn determined by the number of clusters present at the time of diagnosis, the entity of the expansion of the mesangium, the expansion capacity and the number of sclerotic glomeruli. Urinary albumin excretion is related to the size of the pores of filtration. The vascular endothelium plays a central role in the regulation of vascular tone. Endothelin (ET) is a potent vasoconstrictor produced by endothelium that contributes to basal vascular tone. Vasoconstriction in response to altered endogenous ET may lead to hyperperfusion and subsequent microvascular damage. Hyperperfusion is one of the keys to the onset and progression of microvascular complications in diabetes. Such a haemodynamic condition can be determined by the excessive release of vasodilator substances, as for example during ketonic decompensation, or for a reduced action of vasoconstrictive substances. This interpretation may be the pathophysiological basis of what has been observed in diabetes. In patients with diabetes there is a deficit of action of ET that, unlike in the normal patient, does not induce vasoconstriction. In fact, individuals with diabetes have levels of ET that would appear to be determined mainly by triglycerides and insulin.

Aminaphtone (2-hydroxy-3-methyl-1,4-napthohydroquinone-2-p-aminobenzoate) is a synthetic molecule derived from four aminobenzoic acids which is currently employed for "capillary disorders" and for chronic venous insufficiency [18]. This drug has recently demonstrated the ability to downregulate ET-1 production in ECV304 cells by interfering with transcription of preproET-1 (PPET-1) gene expression [19]. At the same time, cytofluorometry has shown that aminaphtone significantly reduces the expression of E-selectin (endothelial-leukocyte adhesion molecule 1; ELAM-1) both in resting and in ET-B -activated ECV304 cells in a dose-dependent manner [20]. In vivo, in patients affected by systemic sclerosis, 12 weeks of aminaphtone treatment has demonstrated the ability to downregulate sELAM-1 (soluble E-selectin adhesion molecules 1) and sVCAM-1 (soluble vascular cell adhesion molecule 1) [21]. In a rat model of monocrotaline-induced pulmonary hypertension, the administration of aminaphtone $(30 \mathrm{mg} / \mathrm{kg} /$ day or $150 \mathrm{mg} / \mathrm{kg} /$ day) significantly lowered rat mortality and significantly reduced plasma ET-1 concentration [22]. Aminaphtone has also demonstrated antiphlogistic activity on endothelial cells [23]. In order to control vascular microangiopathy in patients affected by
IDDM with proteinuria and hypertension, we added aminaphtone to standard therapy for IDDM (insulin) and hypertension (angiotensin-converting enzyme inhibitors).

\section{Case presentation}

A 49-year-old white man with type 1 diabetes has, from the age of 20, been treated with NovoRapid (insulin aspart; $3 \mathrm{U}$ breakfast time, $8 \mathrm{U}$ lunch time, and $10 \mathrm{U}$ dinner time) and Lantus' (insulin glargine; 14U 10 p.m.) for glycaemic control for more than 20 years. He has been hypertensive since 2006 and receives treatment with ramipril: one tablet $5 \mathrm{mg}$ at breakfast time. He has also been treated with Torvast (atorvastatin; one tablet $10 \mathrm{mg} /$ day) for hypercholesterolaemia. Microalbuminuria has been present in this patient since 2006 independently of any pharmacological treatments; no alterations have been reported in his fundus oculi during the time. An examination of his nailfold periungual videocapillaroscopy shows the presence of beanpole loops with dilated venous tract and presence of pearl-like microbleeds with clear signs of microangiopathy (Figure 1). His microalbuminuria value was $487.1 \mathrm{mg} / \mathrm{L}$; GFR was under $58 \mathrm{~mL} / \mathrm{minute}$; creatinine was $1.31 \mathrm{mg} / \mathrm{dL}$ and arterial blood pressure was $140 / 85 \mathrm{mmHg}$. He began treatment with aminaphtone $75 \mathrm{mg}$ one tablet twice a day for 2 months. After 2 months of therapy he was re-evaluated by videocapillaroscopic examination showing a clear resolution of profuse bleeding (Figure 2). At the same time his microalbuminuria value significantly decreased $(98.3 \mathrm{mg} / \mathrm{L})$; his GFR (under $57 \mathrm{~mL} / \mathrm{minute}$ ) and creatinine $(1.33 \mathrm{mg} / \mathrm{dL}$ ) were substantially unchanged but his arterial blood pressure decreased to $130 / 80 \mathrm{mmHg}$. Taking into account the results obtained with the above treatment, he continues to take aminaphtone; however, intake was spontaneously interrupted for 2 months. After 2 months without aminaphtone treatment he repeated proteinuria evaluation: his microalbuminuria significantly increased to $573.0 \mathrm{mg} / \mathrm{L}$ while his GFR (under $58 \mathrm{~mL} /$ minute) and creatinine $(1.31 \mathrm{mg} / \mathrm{dL})$ were unchanged and his arterial blood pressure again increased to $140 / 85 \mathrm{mmHg}$. No side effects related to aminaphtone were detected during the trial.

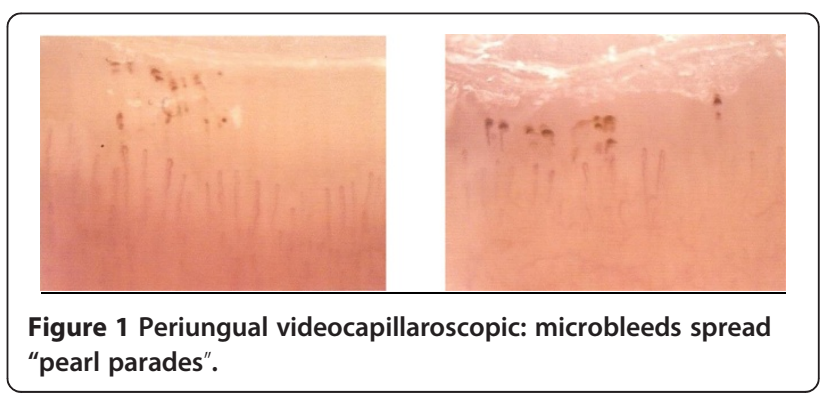




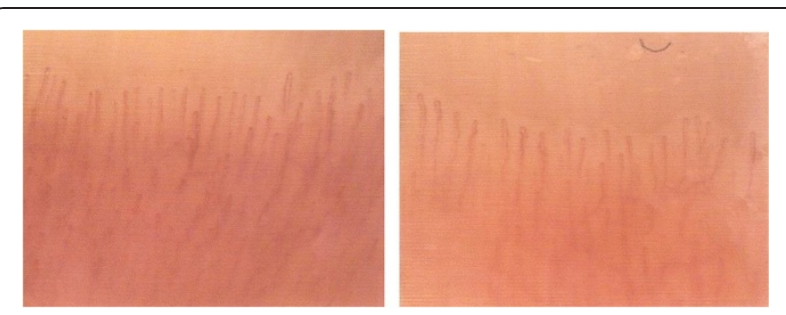

Figure 2 Periungual videocapillaroscopic: resolution of profuse bleeding.

\section{Discussion}

This case report initially describes a significant reduction of proteinuria in a patient with diabetes type 1 , due to the use of aminaphtone. Our patient was first evaluated after 2 months of treatment (aminaphtone capsules $75 \mathrm{mg}$ twice a day), showing a significant decrease in microalbuminuria (from $487.1 \mathrm{mg} / \mathrm{dL}$ to $98.3 \mathrm{mg} / \mathrm{dL}=-388.8 \mathrm{mg} / \mathrm{dL}$ ) confirmed by an improvement in the capillaroscopic examination, while GFR and creatinine remained substantially unchanged. Surprisingly, arterial blood pressure decreased from $140 / 85 \mathrm{mmHg}$ to $130 / 80 \mathrm{mmHg}$ after treatment. Subsequently, he continued treatment with aminaphtone for 2 months, but spontaneously interrupted the treatment. He was re-evaluated 2 months after discontinuation of the drug and, again, showed an increase in proteinuria (from $98.3 \mathrm{mg} / \mathrm{dL}$ to $573 \mathrm{mg} / \mathrm{dL}=+474.7 \mathrm{mg} / \mathrm{dL}$ ), substantially the same GFR and creatinine values, and a new increase in arterial blood pressure to $140 / 85 \mathrm{mmHg}$ : this kind of re-challenge clearly demonstrates the relationship between proteinuria and aminaphtone therapy. The recent preclinical findings about aminaphtone (anti-ET-1 and anti-E-selectin activities together with a significant endothelial antiphlogistic effect) [19-23] seem to correlate with this result, confirming that microangiopathy is the leading cause of microalbuminuria in patients with IDDM.

\section{Conclusions}

Aminaphtone therapy seems to be useful for proteinuria control in patients with type 1 diabetes. The correlation between proteinuria and arterial blood pressure that significantly decreased after aminaphtone treatment and increased once treatment was stopped was surprising. To the best of our knowledge, descriptions of aminaphtone's activity have not included a report of a novel therapeutic option. For the purposes of therapeutic effectiveness, the duration of treatment (more than 2 months) together with the compliance of daily administration of the drug appears to be relevant. Further controlled studies, including randomised double-blind controlled trials, are needed to definitively evaluate aminaphtone's efficacy over the long term in patients with IDDM. Nevertheless, the lesson to take from this case report is that a pharmacological treatment of diabetic microangiopathy with a vascular drug like aminaphtone could be useful for proteinuria control postponing IDDM nephrologic complications.

\section{Consent}

Written informed consent was obtained from the patient for publication of this case report and accompanying images. A copy of the written consent is available for review by the Editor-in-Chief of this journal.

\section{Abbreviations}

ET: Endothelin; GFR: Glomerular filtration rate; IDDM: Insulin-dependent diabetes mellitus.

\section{Competing interests}

C Romano, C Tamburella, M Costa, M Messina and AL Fassari declare that they have no competing interests.

Marco Bertini has competing interests because he is the Medical Department Director of Laboratori Baldacci, the company that produces aminaphtone.

\section{Authors' contributions}

$C R, C T, M C$ and MM clinically followed the patient during his hospitalisation time; CR performed videocapillaroscopy examination; ALF followed the time course of the retinal complications of the patient; MB conceived of the study, collected the data and helped to draft the manuscript. All authors read and approved the final manuscript.

\section{Acknowledgments}

We would like to thank Mr Alessandro Moscatelli for his technical support in preparing the final manuscript.

\section{Author details}

'Department of Cardiology, Acireale Hospital, Provincial Health Centre of Catania, Catania, Italy. ${ }^{2}$ Department of Ophthalmology, Acireale Hospital, Provincial Health Centre of Catania, Catania, Italy. ${ }^{3}$ Medical Department, Laboratori Baldacci SpA, Via San Michele degli Scalzi 73, 56124 Pisa, Italy.

Received: 2 July 2014 Accepted: 30 October 2014

Published: 19 December 2014

\section{References}

1. Kofoed-Enevoldsen A, Borch-Johnsen K, Kreiner S, Nerup J, Deckert T: Declining incidence of proteinuria in type 1 (insulin-dependent) diabetic patients in Denmark. Diabetes 1987, 36:205-209.

2. Krolewski AS, Caressa N, Warram JH, Laeffe LMB, Christlieb AR, Knowler WC, Rand LI: Predisposition to hypertension and susceptibility to renal disease in insulin-dependent diabetes. N Engl J Med 1988, 318:140-145.

3. Myers BD, Winets JA, Chui F, Michaels AS: Mechanism of proteinuria in diabetic nephropathy: a study of glomerular barrier function. Kidney int 1982, 21:633-641.

4. Viberti GC, Hill RD, Jarrett RJ, Argyropoulos A, Mahmud U, Keen H: Microalbuminuria as a predictor of clinical nephropathy in insulin-dependent diabetes mellitus. Lancet 1982, i:1430-1432.

5. Ritz E: Nephropaty in type 2 diabetes. J Int Med 1999, 245:111-126.

6. Alzaid AA: Microalbuminuria in patients with NIDDM: an overview (Review). Diabetes Care 1996, 19:69-89.

7. American Diabetes Association: Diabetic nephropathy (Position Statement). Diabetes Care 2000, 23(Suppl. 1):S29-S72.

8. Mogensen CE: Microalbuminuria, blood pressure and diabetic renal disease: origin and development of ideas. Diabetologia 1999, 42:263-285.

9. Ritz E, Reinhold O: Nephropathy in patients with type 2 diabetes mellitus. N Engl J Med 1999, 341:1127-1133.

10. Niskanen LK, Penttila I, Parviainen M, Vusitupa MIJ: Evolution, risk factors, and prognostic implications of albuminuria in NIDDM. Diabetes Care 1996, 19:486-493.

11. The Microalbuminuria Collaborative Study Group: Predictors of the development of microalbuminuria in patients with type 1 diabetes mellitus: a seven-year prospective study. Diabet Med 1999, 16:918-925. 
12. Klein R, Klein BE, Moss SE: Relation of glycemic control to diabetic microvascular complications in diabetes mellitus. Ann Intern Med 1996, 124:90-96.

13. Villar G, Garcia Y, Goicolea I, Vasquez JA: Determinants of development of microalbuminuria in normotensive patients with type 1 and type 2 diabetes. Diabet Metab 1999, 25:246-254.

14. Warram JH, Scott L, Hanna LS, Wantam M, Cohen SE, Laffel LMB, Ryan L, Krolewski AS: Progression of microalbuminuria to proteinuria in type 1 diabetes: nonlinear relationship with hyperglycemia. Diabetes 2000, 49:94-100.

15. Ismail N, Beckner B, Strtzelczyk P, Ritz E: Renal disease and hypertension in non-insulin-dependent diabetes mellitus. Kidney Int 1999, 55:1-28.

16. Caramori ML, Fioretto P, Mauer M: The need for early predictors of diabetic nephropathy risk. Diabetes 2000, 49(9):1399-1408.

17. Olgemoller B, Schleicher E: Alterations of glomerular proteins in the pathogenesis of diabetic nephropathy. Clin Invest 1993, 71:S13-S19.

18. Atenas JG: The efficacy of aminaphtone in patients suffering from chronic venous insufficiency. Ann Exp Clin Med 1995, 2:81-85.

19. Scorza R, Santaniello A, Salazar G, Lenna S, Colombo G, Turcatti F, Beretta L: Aminaftone, a derivative of 4-aminobenzoic acid, downregulates endothelin-1 production in ECV304 Cells: an in vitro Study. Drugs RD 2008, 9(4):251-257.

20. Lenna S, Salazar G, Della Bella S, Antonioli R, Beretta L, Santaniello A, Scorza R: Novel Mode of Action of The Aminaphtone: Down-Regulation of E-Selectin expression in ECV304 Cells. Lisbon (Portugal): Abstract Book of the XXII World Congress of the International Union of Angiology; 2006.

21. Scorza R, Santaniello A, Salazar G, Lenna S, Della Bella S, Antonioli R, Toussoun K, Beretta L: Effects of aminaftone $75 \mathrm{mg}$ TID on soluble adhesion molecules: a 12-week, randomized, open label pilot study in patients with systemic sclerosis. Clin Ther 2008, 30(5):924-929.

22. Zambelli V, Santaniello A, Fumagalli F, Masson S, Scorza R, Beretta L, Latini R. Efficacy of aminaftone in a rat model of monocrotaline-induced pulmonary hypertension. Eur J Pharmacol 2011, 667:287-291.

23. Scorza R, Salazar G, Bellocchi C: Aminaftone: un possibile ruolo nella sclerosi sistemica? Gruppo Italiano per la Lotta alla Sclerodermia (GILS). Rubrica Medica - Giugno 2013.

doi:10.1186/1752-1947-8-443

Cite this article as: Romano et al:: Aminaphtone therapy in patients with type 1 diabetes and albuminuria: a case report. Journal of Medical Case Reports 2014 8:443

\section{Submit your next manuscript to BioMed Central and take full advantage of:}

- Convenient online submission

- Thorough peer review

- No space constraints or color figure charges

- Immediate publication on acceptance

- Inclusion in PubMed, CAS, Scopus and Google Scholar

- Research which is freely available for redistribution 